\title{
Armas para salvar hombres, imágenes para someterlos
}

\author{
Ana Císcar Cebriáa \\ ${ }^{1}$ Universitat Politècnica de València \\ ancisceb@alumni.upv.es
}

\begin{abstract}
The work presented here - Weapons to save men, images to subdue them - is an audiovisual piece of five minutes that reflects on how the processes of progress and rationalization that began with the Enlightenment project have meant and continue to mean, in the same way, barbarism.

The title refers to declarations made by the inventor of the first machine gun, Richard Jordan Gatling, in which he justified his invention by the saving of soldiers' lives that his new automatic rifle would mean, because it would require fewer combatants in battle. In this contradictory argument in which it is proposed that the use of a weapon can save lives, the main thesis of the project arises.

The video is composed of appropriate images in which we see, for example, some photographic studies on the movement of Etienne Jules-Marey, as well as the photographic revolver he invented, the video of Operation Teapot in 1955 in which the effects of the nuclear bomb were tested in the reproduction of a village, or war simulators used in the army. Using collage as the main technique of montage and a deconstructive strategy of appropriate material - the images are cut, superimposed and juxtaposed in a plastic way - relations and contrasts are established between the different materials that compose the video.
\end{abstract}

Keywords: video, collage, progress, barbarism, war.

\section{Resumen}

El trabajo que aquí se presenta -Armas para salvar hombres, imágenes para someterlos- se trata de una pieza audiovisual de cinco minutos, en la que se plantea una reflexión acerca de cómo los procesos de progreso y racionalización que comenzaron con el proyecto de la llustración, supusieron y suponen, del mismo modo, la barbarie. 
El título hace referencia a unas declaraciones del inventor de la primera ametralladora, Richard Jordan Gatling, en las que justificaba su invento por el ahorro de vidas en soldados que iba a suponer su nuevo fusil automático al necesitar en batalla menos combatientes. En este contradictorio argumento en el que se propone que el uso de un arma pueda salvar vidas surge la tesis principal del proyecto.

El vídeo se compone de imágenes apropiadas en las que vemos, por ejemplo, algunos estudios fotográficos sobre el movimiento de Etienne Jules-Marey, así como el revólver fotográfico que inventó, el vídeo de la Operación Teapot de 1955 en los que se probaron los efectos de la bomba nuclear en la reproducción de un poblado, o simuladores de guerra que utilizan en el ejército. Utilizando el collage como técnica principal de montaje y estrategia deconstructiva del material apropiado-las imágenes se cortan, superponen y yuxtaponen de un modo plástico-, se establecen relaciones y contrastes entre los diferentes materiales que componen el vídeo.

Palabras clave: vídeo, collage, progreso, barbarie, guerra.

\section{Introducción}

En el presente artículo analizaremos de forma breve, tanto los aspectos más teóricos, como formales, del proyecto videográfico Armas para salvar hombres, imágenes para someterlos (2019).

Se trata de una pieza audiovisual, de cinco minutos de duración, en la que se explora, mediante el uso de imágenes apropiadas y la técnica del video-collage, la relación intrínseca entre los procesos de progreso y racionalización, con la barbarie. En concreto, el vídeo establece una cierta analogía entre los métodos de producción de imágenes, -cámaras, simuladores...-con métodos violentamente destructores.

Este proyecto audiovisual forma parte de la línea de investigación que estoy llevando a cabo desde mi trabajo como artista visual, en la que se abordan los peligros inherentes que existen detrás de cada imagen, analizando como su evolución técnica participa directamente en la "destrucción del hombre" (Didi-Huberman, 2013, p. 28), y relacionándola con los actuales métodos de producción masivos que las generan.

El título del vídeo hace referencia a unas declaraciones del inventor de la primera ametralladora, Richard Jordan Gatling, en las que justificaba su invento por el ahorro de vidas en soldados que iba a suponer su nuevo fusil automático al necesitar en batalla menos combatientes. Aparte de este contradictorio argumento racionalista en el que se propone que el uso de un arma pueda salvar vidas, se plantea el vínculo entre armas e 
imágenes, además de poner en relieve como, en muchas ocasiones, son las imágenes las armas generadoras de destrucción y violencia.

Bajo esta premisa, la pieza está compuesta por diferentes vídeos apropiados de la red, en los que vemos algunos de los primeros estudios fotográficos sobre el movimiento de Etienne Jules-Marey, así como el revólver fotográfico que inventó, el vídeo de la Operación Teapot de 1955 en los que se probaron los efectos de la bomba, simuladores de guerra que utilizan en el ejército, el primer videojuego de temática bélica, o anuncios de los años sesenta de juguetes de armas de fuego.

Mediante el uso del collage como técnica principal de montaje y estrategia deconstructiva $-\mathrm{y}$ resignificativa- de éste material apropiado, se establecen una serie de relaciones, por contraste en unas ocasiones, y por similitud en otras, en las que se observa claramente esa navaja de doble filo que es el progreso, y cómo los procesos de racionalización y tecnificación no sólo han desarrollado avances benevolentes, también han seguido desencadenando, con una eficiencia aterradora, guerras, violencia e injusticia.

\section{La guerra con / desde / a través de las imágenes}

El vídeo, estructurado en tres partes claramente diferenciadas por la temática de las imágenes y por el montaje de éstas, comienza con los primeros estudios fotográficos sobre el movimiento de Etienne Jules-Marey, cuya técnica, la cronofotografía, permitió hacer visible lo que para entonces el ojo era incapaz de ver, posibilitando así la representación de ciertas fases del movimiento. Las imágenes que vemos en esta primera parte, fragmentadas y superpuestas entre sí, se van sucediendo en un juego acumulativo. Vemos diferentes animales en movimiento, el caminar de un caballo, el estudio de su salto, un colaborador de Jules-Marey pronunciando je vous aime, y al propio investigador con uno de sus inventos más recordados, el fusil fotográfico, con el que registraba estas cronofotografías. El diseño del aparato permitía poder disparar doce fotografías por segundo y registrarlas en un mismo cuadro. Al igual que con una cámara al uso, vemos a Jules-Marey visualizar su objetivo, apuntar, ajustar y apretar el disparador, en este caso, un gatillo.

Estas imágenes muestran de un modo muy literal la violencia simbólica que está detrás del obturador fotográfico, y que, con el paso del tiempo y la tecnificación de los dispositivos, se ha convertido en algo más palpable que nunca. Susan Sontag escribía en 1996: "Hay algo predatorio en el acto de registrar una imagen. Fotografiar personas es violarlas, pues [las] transforma en objetos que pueden ser poseídos simbólicamente" (Sontag, 1996, p. 24). De este modo, la fotografía -podíamos hablar también de otro tipo de representaciones icónicas-, con su afán cazador por registrar fragmentos del 
mundo, es un medio poderosamente violento y peligroso, capaz de transformar aquello que fotografía desde el dominio de la mirada del fotógrafo.
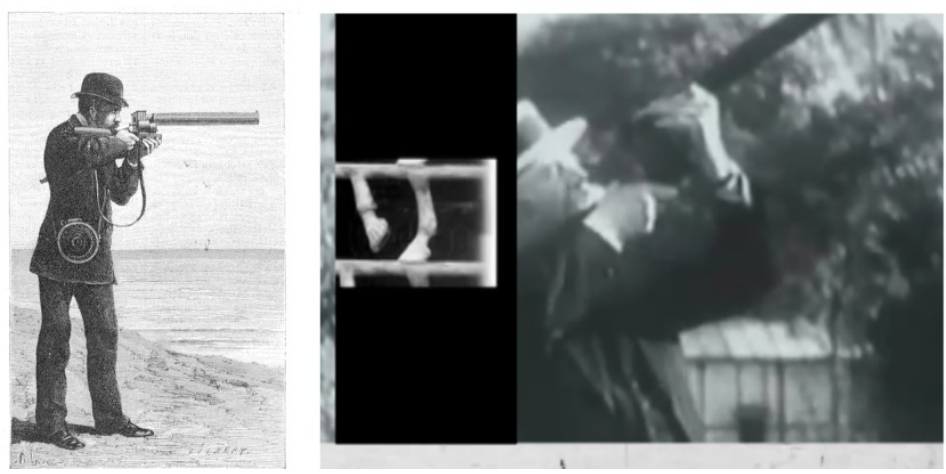

Fig. 1: Fusil fotográfico, 1882;

Fig. 2: Captura del vídeo Armas para salvar hombres, imágenes para someterlos (2019).

Este primer minuto del vídeo, en el que vemos los registros del fusil fotográfico de Jules-Marey, nos advierte del potencial destructor de un mundo altamente tecnificado, y de cómo las imágenes, así como los dispositivos que las producen, son partícipes de ello.

Acto seguido, comienza la segunda parte de la pieza en la que se van intercalando, también mediante superposición, imágenes de la Operación Teapot de 1955 en los que se probaron los efectos de bombas nucleares llevadas a cabo en El Sitio de Pruebas de Nevada (una reserva militar creada para probar armas atómicas); junto a imágenes de un simulador con aspecto de videojuego que utilizan normalmente en el ejército como entrenamiento; y, las primeras imágenes del espacio registradas en 1946.
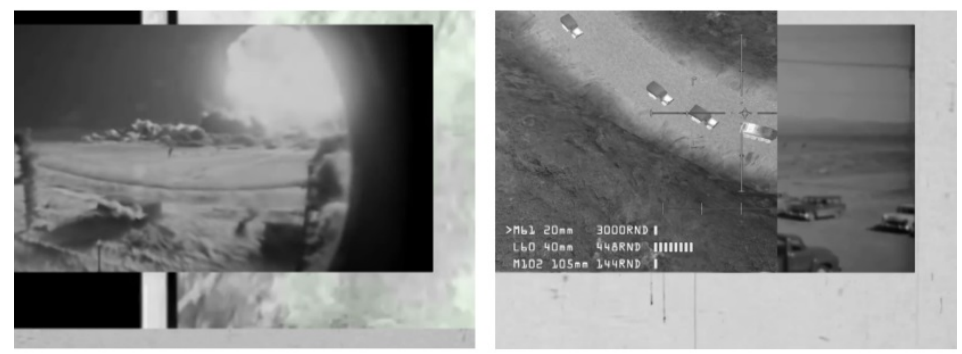

Fig. 3: Capturas del vídeo Armas para salvar hombres, imágenes para someterlos (2019).

Con esta serie de vídeos vemos muy claramente la evolución simultánea y la sinergia entre los dispositivos de captura de imágenes, y los avances en la industria militar. 
Además, se tratan de grabaciones con cierto carácter ficticio o simulado -en el caso del simulador militar, y las pruebas atómicas en un poblado teatralizado-, con el objetivo de entrenar a los soldados, o ver la fuerza destructiva de las armas atómicas, dándole a la representación un carácter doblemente violento, por su fin instrumental, y simbólico. Tal y como afirma Weizenbaum, uno de los padres de la cibernética, "una herramienta siempre es a la vez un modelo de su propia reproducción y una instrucción de uso para la aplicación de las capacidades que simboliza (...) La herramienta como símbolo trasciende así un rol como un medio práctico para un fin determinado y es un elemento constitutivo para la recreación simbólica del mundo por parte de las personas" (Weizenbaum, como se citó en Farocki, 2013, p. 105).

Este es un tema ampliamente abordado por el artista Harun Farocki, uno de los referentes más evidentes a la hora de plantear el proyecto videográfico que aquí se analiza. El cineasta alemán, vertebrará su discurso a lo largo de prácticamente toda su carrera con la relación entre las "fuerzas productivas y las fuerzas destructivas", en las que "guerra y crecimiento del capital se abrazan, entrelazan y determinan mutuamente como parte del mismo sistema, de un mismo movimiento, de una misma expansiva racionalidad" (Collingwood-Selby, 2014, p. 60). Mediante el uso de imágenes operativas, como por ejemplo en la trilogía Eye/Machine (2001-2004), Farocki pone en evidencia el poder y la peligrosidad de este tipo de dispositivos altamente tecnificados, donde se pierde por completo la parte subjetiva e humanizada, y que han alimentado con gran eficiencia "la dinámica destructiva puesta en marcha por el conflicto" (Benet, 2007, p. 47). El cineasta alemán bebe directamente de la línea discursiva proveniente en gran parte de la Teoría Crítica de la Escuela de Frankfurt, más concretamente de la línea contra la ideología tecnocrática que desarrollaron más en profundidad autores como Marcuse, o Habermas. Estos autores hablaban de cómo se estaba legitimando el dominio del hombre, gracias a la ciencia y la técnica, en tanto generadoras de riqueza en la sociedad capitalista: "En esta sociedad, el aparato productivo tiende a hacerse totalitario en la medida en que determina, no sólo las ocupaciones, aptitudes y actitudes socialmente necesarias, sino también las necesidades y aspiraciones individuales (...) La tecnología sirve para instituir formas de control social y de cohesión social más efectivas y más agradables" (Marcuse, 2016, p. 36).

Esta segunda parte del vídeo concluye con el despegue del cohete que permitió registrar las primeras imágenes del espacio exterior, un gran hito de avance y poder técnico, mientras vemos, simultáneamente, los muñecos del poblado de Nevada arder por la explosión atómica.

Por último, la parte final de la pieza se compone de un reportaje francés sobre la Guerra Civil Española, anuncios de diferentes juguetes de armas de fuego de los años cincuenta y setenta, y uno de los primeros videojuegos de temática belicista. 
Como hemos visto, muchos de los videos apropiados que conforman el proyecto, aparte de los que son claramente registros documentales de diferentes situaciones y contextos históricos, se caracterizan por cumplir esa función de simulacro, como el caso del simulador militar, o las pruebas nucleares. Del mismo modo, podríamos decir que tanto los anuncios de juguetes, como el videojuego, tienen el mismo carácter: ambos tienen ese componente teatral y representativo intrínseco a las dinámicas del juego. Pese a esta similitud, hay algo que los distingue, y es, precisamente, su supuesto fin lúdico.

La macabra comparación que crean estas imágenes con las del reportaje sobre la Guerra Civil Española, como si de otro juego de niños se tratara, hace que nos cuestionemos sobre la peligrosa influencia de este tipo de juegos o representaciones basadas en el imaginario bélico, no tanto por su reproducción literal, sino por la recreación simbólica que crean, tal y como afirmaba Weizenbaum, participando en una lectura belicista de la Historia que justifica y normaliza el conflicto.
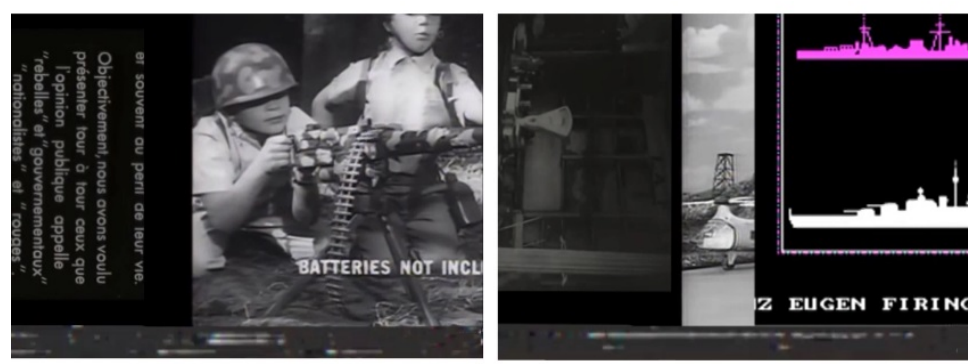

Fig. 4: Capturas del vídeo Armas para salvar hombres, imágenes para someterlos (2019).

\section{El uso del collage como técnica del montaje}

Como hemos comentado, una de las características formales más destacas del proyecto es la utilización del collage como técnica principal de montaje, la cual no sólo nos ha servido como una herramienta compositiva, sino también como un elemento clave en las relaciones dialécticas que se han generado entre las imágenes apropiadas.

Así pues, los recursos más utilizados serían, por una parte, la fragmentación del material apropiado, recortando los vídeos a diferentes tamaños, como si de un papel se tratara; y la sucesión de las imágenes de un modo acumulativo, donde éstas, no sólo aparecen de manera simultánea, sino que se yuxtaponen unas encimas de otras. También se han modificado los modos de reproducción de algunos de los vídeos, 
poniéndolos marcha atrás, y otros son girados 180 ․ Este juego compositivo, podríamos decir, constructivista, hace del montaje una herramienta más intuitiva y plástica, sin regirse por las lógicas ortodoxas, destacando elementos que normalmente pasarían desapercibidos, como los márgenes negros de los diferentes formatos de cada vídeo.

Por otra parte, en cuanto a las relaciones que se establecen entre el material apropiado, se ha intentado generar a lo largo de todo el proyecto una suerte de arqueología visual mediante el montaje poniendo fragmentos de un material heterogéneo, y de contextos y tiempos diferentes con el fin de crear contrastes y diálogos entre las imágenes. Los saltos temporales, los choques y confrontaciones no son otra cosa que una interrogación, un cuestionamiento a ciertos imperativos visuales con un potencial predatorio; un cuestionamiento a esa mirada técnica que nos enseña qué y cómo tenemos que percibir y entender aquello que nos rodea.

\section{Conclusiones}

En el ensayo Cuando las imágenes toman posición, en el que el filósofo Didi-Huberman analiza la obra más visual de Berltolt Brechtch, habla de lo que el poeta alemán denominó como un "arte de la historización", "un arte que rompe la continuidad de las narraciones, extrae de ellas diferencias y, al componer esas diferencias juntas, restituye el valor esencialmente "críptico" de toda historicidad. Distancias en saber manipular el material visual y narrativo como un montaje de citas que hacen referencia a la historia real" (Didi-Huberman, 2013, p. 62).

Es esta "ruptura de la continuidad" la que se ha propuesto a lo largo de todo el proyecto, una ruptura que se ha planteado dualmente, desde los saltos y los contrastes temporales entre el material apropiado, y de un modo literal, mediante la fragmentación de dicho material.

Gracias al distanciamiento que permite la apropiación de un material visual alejado de nuestro tiempo, en contraste con imágenes contemporáneas, que nos tocan e interpelan de un modo más directo, podemos arrojar una mirada crítica sobre esas imágenes que participan activamente en contextos de violencia, además de cuestionar la historia contada a través del relato belicista imperante. 


\section{Referencias}

CELIS BUENO, C. (2016). Imágenes operativas y montaje blando: historicidad de la función social de la imagen en la obra de Harun Farocki. AISTHESIS. 60, 91-109.

COLLINFWOOD-SELBY, E. (2014). Reconocer y perseguir de Harun Farocki: el dominio de la imagen operativa. En D. Fernández Sobre Harun Farocki. La continuidad de la guerra a través de las imágenes. Santiago de Chile: Metales Pesados.

DIDI-HUBERMAN, G. (2012). Arde la imagen. Oaxaca: Ediciones Ve S.A.

DIDI-HUBERMAN, G. (2013). Cuando las imágenes toman posición. Madrid: A. Machado Libros.

FAROCKI, H. (2013). Desconfiar de las imágenes. Argentina: La Caja Negra editora

GARCÍA, L. (2017). La comunidad en montaje: George Didi-Huberman y la política de las imágenes. AISTHESIS, 61, 93-117.

GUARDIOLA, I. (2019). El ojo y la navaja. Un ensayo sobre el mundo como interfaz. Barcelona: Arcadia

HABERMAS, J. (2009). Ciencia y técnica como "ideología". Madrid: Tecnos.

HERNÁNDEZ, M. (2012). Materializar el pasado. El artista como historiador (benjaminiano). Murcia: Micromegas .

MARCUSE, H. (2016). El hombre unidimensional. Barcelona: Planeta.

MARTíNEZ LUNA, S. (2019). Cultura visual, la pregunta por la imagen. Vitoria-Gasteiz: Sans Solei Ediciones.

SONTAG, S. (1996) Sobre la fotografía. Barcelona: Edhasa.

VIRILIO, P. (1989). La máquina de visión. Madrid: Cátedra.

VIRILIO, P. (2012). La administración del miedo. Madrid: Pasos Perdidos Barataria. 